\title{
Brasil y la nueva generación de Acuer- dos de Cooperación y Facilitación de Inversiones: un análisis del Tratado con México ${ }^{1}$
}

\author{
Brazil and the new generation of Cooperation and Facilitation \\ Investment Agreements: an analisys of the Treaty with Mexico
}

\section{Alberto Arroyo Picard ${ }^{2}$ y Luciana Ghiotto ${ }^{3}$}

\begin{abstract}
Resumen: El objetivo de este artículo es presentar las cláusulas del Acuerdo de Cooperación y Facilitación de las Inversiones (ACFI) firmado entre Brasil y México en 2015, y compararlo con las cláusulas de los Tratados Bilaterales de Inversión (TBI) firmados en los años noventa. Se indica que el ACFI pertenece a la "nueva generación de acuerdos sobre inversión". Si bien el ACFI posee características novedosas, mantiene cláusulas similares a los TBI como el Trato Nacional y Trato de Nación Más Favorecida, y no incluye obligaciones vinculantes para los inversionistas y sus inversiones. Se pone especial énfasis analítico en el sistema de solución de controversias propuesto.
\end{abstract}

Summary: This article analyses the Agreement on Cooperation and Facilitation of Investments signed between Brazil and Mexico in 2015. We develop a comparison between this Agreement and the standard clauses of Bilateral Investment Treaties (BIT). It is stated that the ACFI belongs to the new generation of investment agreements. But even if these new agreements present some novelties, they still contain clauses that are similar to those that are present in BITs, such as National Treatment and Most Favoured Nation clauses; also, they present no obligations for investors and their investments. We emphasize the special characteristics of the dispute settlement mechanism proposed.

Palabras clave: Acuerdo de Cooperación y Facilitación de las Inversiones, Brasil, México - TBI - inversiones

Key words: Agreement on Cooperation and Facilitation of Investments - Brazil Mexico, Bilateral Investment Treaty, investments

${ }^{1}$ Recibido: 09/08/2016 Aprobado: 10/04/2017

${ }^{2}$ Maestro en Sociología, con estudios de doctorado en Ciencias Sociales. Investigador titular C de la UAM, México. Miembro comisionado de la Comisión para la Auditoría Integral Ciudadana de los Tratados de Inversiones y del Sistema de Arbitraje (CAITISA), Ecuador.

${ }^{3}$ Doctora en Ciencias Sociales (UBA). Investigadora adjunta de FLACSO-Argentina. Asesora externa de la Comisión para la Auditoría Integral Ciudadana de los Tratados de Inversiones y del Sistema de Arbitraje (CAITISA), Ecuador. 


\section{Consideraciones iniciales}

Actualmente presenciamos un debate político y académico sobre uno de los pilares ideológicos de los años noventa, que aseguraba la existencia de una relación causal entre la firma de Tratados Bilaterales de Inversión (TBI) y el aumento en los flujos de la Inversión Extranjera Directa (IED). Gran parte de los Estados habían aceptado esta lógica, creyendo que la firma de TBI, al ofrecer la seguridad jurídica buscada por los inversionistas, aumentaría su credibilidad externa y con ello se garantizarían crecientes flujos de capitales extranjeros. Esta premisa parecía confirmarse ya que durante la década de los noventa hubo un aumento de la IED en América Latina y el Caribe. Sin embargo, la coincidencia en el tiempo entre aumento de firmas de TBI y de flujos de inversión no necesariamente indica un relación determinante entre ambos. Actualmente una parte importante de la literatura académica confirma que no se puede demostrar una relación causal entre estos dos elementos (Hallward-Driemeier, 2003; Yackee, 2010; Poulsen, 2010). Un análisis más profundo muestra que la llegada de IED arribó por múltiples factores y no solo por la firma de los TBI. En muchos casos, un factor fundamental fueron los acelerados procesos de privatizaciones de empresas y servicios públicos. Por ejemplo, en el caso de Ecuador es claro que los TBI no son los determinantes de la llegada de IED, más aún, la mayoría de estas inversiones viene de países con los que no se tiene ningún TBI (CAITISA, 2015).

Asimismo, algunos organismos internacionales han puesto en cuestión esta supuesta relación causal. La UNCTAD, por ejemplo, sostiene que los TBI no son un instrumento de política suficiente para atraer la IED, ya que existirían otros determinantes más importantes en el país anfitrión, en particular los determinantes económicos (UNCTAD, 2014). Por su parte, la CEPAL en sus últimos informes sobre la IED en América Latina analiza otros determinantes para la toma de decisiones acerca de dónde invertir en el exterior (Arroyo, 2013; CEPAL, 2012). De este modo, los estudios sistemáticos sobre inversiones no sólo cuestionan la relación causal directa entre TBI y aumento de los flujos de IED, sino que ponen en el centro del debate si bajo las reglas de los TBI la inversión tiene los efectos esperados sobre las economías de los países receptores.

En América Latina, Brasil ha sido prueba notoria de que dicha relación causal es al menos cuestionable. Efectivamente, este país es el principal receptor y emisor de IED en América Latina, y no tiene ningún TBI en vigencia ${ }^{4}$. Sin embargo, esta realidad ha cambiado, ya que Brasil negoció recientemente cinco tratados de inversión: con Mozambique, Angola, México, Chile y Colombia, todos en el año $2015^{5}$.

${ }^{4}$ Esta afirmación debe ser matizada. Entre 1994 y 1999 Brasil negocio y firmó 14 TBI, pero una fuerte oposición política en el Congreso impidió que dichos acuerdos entraran en vigencia. Sin embargo, es importante señalar que a pesar de que no se ratificaran los TBI, en 1995 el Congreso brasileño aprobó una enmienda constitucional que eliminaba cualquier tipo de discriminación contra inversores extranjeros, lo cual sería equivalente a las cláusulas de los TBI de Trato Nacional y Trato Justo y Equitativo a las inversiones extranjeras. Además, en tanto parte del Mercosur, Brasil está sometido al Tratado de Libre Comercio (TLC) con Israel y negoció (pero aún no han sido ratificados) otros con Egipto y Marruecos. Estos TLC sostienen cláusulas que definen la inversión de un modo similar a los TBI y TLC tradicionales. No obstante, no contienen cláusulas de solución de controversias inversor-Estado y en general en materia de inversión no van más allá de lo ya comprometido en el marco de la OMC. Estos datos muestran que la no existencia de TBI no significa que Brasil no haya mantenido un marco de seguridad jurídica para la IED.

${ }^{5}$ En la reunión de abril de 2017 en Buenos Aires, el MERCOSUR firmó un acuerdo intra-bloque sobre inversiones, que lleva el nombre de Protocolo de Cooperación y Facilitación de Inversiones, que tiene 
Frente a estos hechos, surge una pregunta: ¿por qué Brasil, que durante alrededor de 25 años se negó a ratificar sus tratados sobre inversiones, ahora avanza en la firma de nuevos tratados? Sostenemos que esto se vincula con el rol que Brasil ocupa actualmente en la región, donde no solo se ha convertido en el principal receptor de IED de la región, sino en el principal inversor externo ${ }^{6}$. Las firmas brasileñas casi duplicaron sus inversiones en el exterior en cinco años, en especial a países de América Latina y de África (Morosini y Ratton, 2015; Arroyo, 2013). Además, Brasil no solo reactiva sus negociaciones de TBI, sino que se ha manifestado a favor del avance de las negociaciones de un TLC con la Unión Europea (UE). En el año 2010, de las 17 empresas latinoamericanas que invirtieron en Europa, 12 son brasileñas (Fleury y Otros, 2010). Frente a esta nueva realidad, se dispararon los debates acerca de la pertinencia de sumarse al sistema de protección de las inversiones (Actis, 2012), sólo que esta vez el objetivo de los acuerdos es proteger a las empresas globales brasileñas, y no solo a las de los países desarrollados en el territorio brasileño.

En este artículo nuestro objetivo es analizar los nuevos acuerdos de protección de inversiones negociados por Brasil, los cuales llevan el nombre de "Acuerdo de Cooperación y de Facilitación de las Inversiones" (en adelante, ACFI). Este tratado propuesto se inserta en la nueva generación de acuerdos sobre inversiones, ya que presenta ciertas diferencias con los firmados masivamente en los años noventa. En particular, nos concentraremos en el ACFI firmado con México revisando las cláusulas de dicho acuerdo y comparándolas con las cláusulas que usualmente poseen los TBI. Con ello, nos interesa revisar críticamente los puntos donde se observa una real novedad en estos acuerdos, así como identificar las líneas de continuidad en lo que respecta a los derechos de los inversionistas ${ }^{7}$.

Resulta relevante analizar en profundidad los ACFI brasileños porque hay actualmente una tendencia mundial a la revisión de los TBI y del sistema de arbitraje. Esta revisión se basa en el reconocimiento de que esos marcos jurídicos no necesariamente han sido beneficiosos para atraer la IED, y lo que es más, que la inversión que llega no ha tenido los efectos esperados. En los últimos años varios Estados se movieron en este sentido. Por un lado, Bolivia, Ecuador y Venezuela iniciaron el rompimiento con este sistema, retirándose del Centro de Arreglo de Diferencias sobre Inversiones (CIADI) y revisando (o directamente denunciando) los TBI vigentes. Ecuador convocó a una Comisión de Auditoría Integral de los Tratados de Inversión y del Sistema de Arbitraje (CAITISA) que trabajó entre 2014 y 2015 con tres ejes: a) revisar la compatibilidad de lo pactado en los TBI ecuatorianos con la Constitución de 2008 y los objetivos del buen vivir; b) examinar las demandas contra el país por parte de empresas extranjeras; c) analizar los efectos reales de la IED sobre la economía de Ecuador (CAITISA, 2015).

un formato similar al aquí presentado. Este Protocolo reemplazaría al Protocolo de Colonia firmado en 1994, el cual era el único instrumento sobre inversiones del bloque. Por su reciente firma, el Protocolo de 2017 no ha sido aún blanco de análisis pormenorizados.

${ }^{6}$ México era el primer receptor de IED en América Latina, pero empezó a perder terreno precisamente en la época de firmas de TBI. En el caso de la IED europea, la situación es aún más clara: en 1998 Brasil rebasó a México como receptor de dichas inversiones y eso se mantiene a pesar de que en el año 2000 México firmó el TLC con la Unión Europea, a la vez que posee TBI con todos los países miembros de este bloque (Arroyo, 2013).

${ }^{7}$ En este artículo no vamos a revisar los efectos del ACFI sobre los flujos de inversión, sino que nos interesa indagar en el marco contractual que ambas Partes han determinado. 
Otros países como Noruega, Sudáfrica, India, Indonesia y Australia han emprendido un proceso de revisión de los marcos establecidos para la negociación de tratados sobre inversión ${ }^{8}$. Es por ello que podemos hablar de una nueva generación de tratados de inversión ${ }^{9}$. El punto más cuestionado ha sido el sistema de solución de controversias inversor-Estado y el arbitraje internacional, pero asimismo introducen nuevas condiciones contractuales que atenúan la amplia cantidad de derechos que los inversionistas poseen en los TBI. También la UNCTAD desde principios de este milenio ha hecho un llamado a la reforma del sistema de protección de inversiones, cuestionando diversas cláusulas de los TBI y proponiendo lineamientos para renegociarlos o negociar otros distintos en el marco de una Nueva Generación de Política sobre Inversiones (UNCTAD, 2013; Ghiotto, 2017). Finalmente, cabe señalar que las organizaciones de la sociedad civil han desarrollado documentos con posturas más radicales que la UNCTAD, proponiendo el retiro de los países del CIADI y la denuncia de todos los tratados.

Seguidamente presentamos de modo analítico el ACFI Brasil-México a la luz de sus cláusulas. La argumentación está orientada a ver los compromisos que Brasil está aceptando a partir de la firma de estos Acuerdos. Posteriormente trazamos conclusiones a partir de comparar estas cláusulas con los TBI tradicionales.

\section{Preámbulo y Objetivos}

Todos los TBI constan de un primer apartado donde se especifican los objetivos del mismo. Allí se establecen ideas generales que constituyen el "espíritu" del tratado. Los preámbulos siempre refieren a objetivos sociales y de desarrollo que se alcanzarán con los TBI e incluso, traslucen la idea de que cualquier inversión sería positiva para un país. Generalmente no se les presta atención debido a que no acarrean derechos y obligaciones legalmente vinculantes. Sin embargo, esto no significa que las palabras de los preámbulos sean irrelevantes. Hoy va tomando fuerza otra doctrina legal que considera que los preámbulos son sustanciales a los TBI y se constituyen en claves de interpretación de sus cláusulas ${ }^{10}$. Este cambio está en consonancia con el Artículo 31 de la Convención de Viena sobre el Derecho de los Tratados (1969), el cual estipula que:

I. Un tratado deberá interpretarse de buena fe conforme al sentido corriente que haya de atribuirse a los términos del tratado en el contexto de estos y teniendo en cuenta su objeto y fin. 2. Para los efectos de la interpretación de un tratado, el contexto comprenderá, además del texto, incluidos su preámbulo y anexos (...).

De este modo, el preámbulo constituye parte del contexto del acuerdo y, por ello, resulta importante al momento de la interpretación. A partir del aumento de las deman-

${ }^{8}$ Otros ejemplos son el Tratado de Inversiones de la ASEAN (2011), así como el proyecto de modelo de tratado para la región de África del Sur.

${ }^{9}$ Cabe remarcar que no todos los TBI que se firman actualmente son de nueva generación, ya que actualmente conviven el viejo modelo junto con el modelo revisado. De todos modos, se puede identificar una nueva ola de revisión del tratado de inversión de los años noventa.

${ }^{10}$ Tal es el caso de Patrick Mitchell vs. El Congo, donde un comité ad-hoc remitió a la cuestión de cuánto había contribuido la inversión al desarrollo del país, para desde allí analizar si calificaba para ser protegida por el tratado (Sornarajah, 2010). 
das de empresas en el Centro Internacional de Arreglo sobre Inversiones (CIADI) en base a los TBI, los preámbulos han cobrado mayor importancia, ya que allí los Estados pueden establecer las características que debe poseer una inversión para ser protegida por los TBI, así como dejar sentados los criterios para su evaluación e incluso elementos que pueden justificar su eventual denuncia.

Desgraciadamente, gran parte de los preámbulos de los TBI cuentan con pocas especificaciones en sus consideraciones previas. Estos hacen referencia, en su mayoría, al entendimiento de que el aumento del flujo de inversiones entre las Partes repercutirá en el desarrollo económico y, por ende, en la prosperidad de ambos.

En el caso de los nuevos acuerdos de Brasil, el nombre mismo ya es significativo: "Acuerdo de Cooperación y de Facilitación de las Inversiones", con lo cual se pretende resaltar que no se trata sólo de atraer, proteger y facilitar las inversiones (tal como en los TBI tradicionales), sino que se instala la idea de que exista una cooperación económica. Esto aparece ya en el Artículo 1, donde se explicita como objetivo del acuerdo "promover la cooperación entre las Partes para facilitar y promover la inversión mutua". Se trata de cooperar para facilitar la inversión, y no sólo "proteger" los intereses de los inversionistas extranjeros ${ }^{11}$.

En el Preámbulo del ACFI, a diferencia de los TBI se reconoce en el párrafo 6 que las Partes tienen el derecho "a legislar en materia de inversiones y adoptar nuevas reglamentaciones (...) con el fin de cumplir con los objetivos de su política nacional". Sin embargo, como veremos más adelante, dicho tratado sigue manteniendo algunas limitaciones de la soberanía nacional para legislar y reglamentar en la materia. El párrafo 3 de dicho preámbulo sostiene como considerando que se reconoce "la necesidad de promover y proteger las inversiones por su papel fundamental en la promoción del desarrollo sostenible, del crecimiento económico, de la reducción de la pobreza, de la creación de empleo, de la expansión de la capacidad productiva y del desarrollo humano". Este párrafo del preámbulo mantiene el supuesto que expusimos al principio de este trabajo: sin IED no hay posibilidad de desarrollo (sostenible) y la firma de un acuerdo (ACFI en este caso) es determinante para atraerla. Como señalamos, este argumento ha sido hoy puesto en duda. Aun así, el ACFI Brasil-México posee esta disposición que mantiene estos argumentos vinculados al discurso neoliberal. A pesar de ello, es importante ya que como señalamos con la Convención de Viena sobre los Tratados, en un futuro se podría argumentar que el "espíritu" del tratado no se cumplió, porque las IED no consiguieron dichos propósitos.

\section{3. Ámbito de aplicación y definición de las inversiones cubiertas (artículos 2 y 3)}

En cuanto al ámbito de aplicación, como prácticamente todos los TBI, el ACFI cubre las inversiones realizadas antes y después de la entrada en vigor del acuerdo. Sin embar-

\footnotetext{
${ }^{11}$ No es Brasil el primero que incorpora este lenguaje en los preámbulos y objetivos. Sólo por citar dos ejemplos, en el TBI de Ecuador-China se dice "se debe intensificar la cooperación económica entre ambos sobre una base de equidad y beneficio mutuo". También en el TBI Ecuador-EEUU se explicita que "es importante reconocer que el desarrollo de los vínculos económicos y comerciales contribuye al bienestar de los trabajadores y promover el respeto por los derechos laborales reconocidos internacionalmente".
} 
go, pone límites que normalmente no se encuentran en los TBI tradicionales, entre los que resaltamos dos:

- No puede ser invocado para asuntos que ya sean cosa juzgada en el ámbito nacional.

- Tampoco podrá ser invocado para asuntos con de más de 5 años de antigüedad.

En la definición de inversión hay diferencias importantes. Veamos la definición:

"Inversión" significa cualquier tipo de bien o derecho perteneciente o bajo control directo o indirecto de un inversionista de una Parte establecido o adquirido de conformidad con las leyes y reglamentos de la otra Parte en el territorio de esa otra Parte, vinculado con la producción de bienes o prestación de servicios en el Estado anfitrión por el inversionista de la otra Parte, con el fin de establecer relaciones económicas de larga duración.

Como vemos, la definición explícitamente excluye la inversión de cartera y cubre solamente "la vinculada a producción o servicios". También excluye las deudas entre Estados. Sin embargo, sí incluye:

- Participaciones en sociedades o empresas. Esto avala la cobertura de las empresas que se hacen cargo de la prestación de servicios públicos (por ejemplo, empresas mixtas o privatizadas), que son inversiones no de tipo greenfield sino inversiones en Mergers \& Aquisitions, fusiones y adquisiciones, que es un tipo de inversión común en momentos de privatizaciones de los servicios públicos, tal como sucedió en varios países latinoamericanos en los años noventa.

- "Bienes raíces u otra propiedad, tangibles o no". Esta definición tan vaga permite una interpretación muy amplia. Los bienes raíces o físicos son la propiedad tangible de un inversor, tales como equipamientos, maquinarias, fábricas, plantaciones, terrenos o bienes materiales en general adquiridos en el territorio de la contraparte. En los TBI, tales bienes aparecen definidos como los bienes muebles e inmuebles y los bienes corporales. Esto es lo que se entiende como IED propiamente dicha. En el caso de los bienes intangibles, su incorporación en los TBI tuvo como objetivo dar protección a la propiedad intelectual sobre patentes, copyright y conocimientos tecnológicos (know-how). Hasta la firma de los TBI, el reconocimiento de la propiedad intelectual dependía de los Estados. Con estos tratados, las compañías se garantizan el reconocimiento inmediato de su propiedad intelectual, sin necesidad de que el Estado receptor haya aprobado, por ejemplo, una patente.

- $\quad$ En cuanto a los Derechos de propiedad intelectual (artículo 3 punto 1.2 c, $d$ y e), el ACFI remite el tratamiento de esta cuestión al piso de los acuerdos de la OMC (Aspectos de Propiedad Intelectual relativos al Comercio, ADPIC). Dado que Brasil es miembro de la OMC no podría excluirse de estas obligaciones, pero, como decíamos, la inclusión de la propiedad intelectual en los TBI responde a la nueva división internacional del trabajo, donde se transfiere tecnología de un país a otro, ya que el producto final va a ser manufacturado en ese país receptor de la inversión. Junto con la inversión se transfiere conocimiento y tecnología patentada en el país de origen, pero no necesariamente patentada en el receptor. Cuando comenzaron a surgir estos problemas, se amplió el concepto de inversión para incluir los bienes intangibles asociados con la propiedad intelectual dentro de los TBI, con el fin de salvar estas diferencias. Es decir, aunque lo acota, Brasil acepta proteger la propiedad intelectual como si fuera una inversión. Asimismo, el ACFI no excluye en materia de 
propiedad intelectual el tema de la producción de medicinas, así como tampoco explicita la preeminencia de las leyes de propiedad intelectual brasileñas en materia de licencias obligatorias para la producción de medicamentos sin fines de lucro.

- Deudas entre empresas interrelacionadas cuidando de excluir las de corto plazo (bonos de menos de tres años) contratados vía bolsa, es decir con carácter especulativo.

- Derechos administrativos (artículo 3 punto $1.2 \mathrm{f}$ ), son los permisos que un Estado debe conceder para que se pueda llevar a cabo una inversión en su territorio (por ejemplo, la concesión para la explotación minera o petrolera). Una empresa no puede operar sin estos permisos, por lo cual se está afectando la inversión. Por ello, los derechos administrativos fueron incluidos en los TBI como parte de una "nueva forma de propiedad" (Sornarajah, 2010). Los TLC y el borrador del fallido Acuerdo Multilateral de Inversiones (AMI) incluyen este tipo de derechos administrativos como un tipo de inversión, el cual es ahora aceptado por Brasil ${ }^{12}$. De todos modos, existe una diferencia entre el ACFI y los TBI clásicos, ya que sólo se cubre "el valor económico de la concesión" y con ello excluye, por ejemplo, litigar sobre las reglamentaciones que pudieran imponer en el futuro a dichas concesiones. Sin embargo, el ACFI deja muy ambigua la definición de valor económico de la concesión, sin haber claridad de si se trata de lo que pagó por la contraprestación o del valor estimado del usufructo que se podría obtener de mantenerse la concesión (que sería equivalente a la "expropiación indirecta" en los TBI). Esto queda para la interpretación.

Finalmente, en cuanto al ingreso o autorización de las inversiones extranjeras, como en casi todos los TBI, cada parte aplicará sus leyes y reglamentos.

\section{El principio de no discriminación}

Bajo el principio transversal de la no discriminación el ACFI incluye, aunque con algunas acotaciones, el principio de Trato Nacional e incluso el de Nación Más Favorecida. Estos principios, que aparecen en todos los TBI y los TLC han sido muy criticados porque, entre otros elementos, limitan la capacidad regulatoria del Estado receptor, además que han sido utilizados por los tribunales arbitrales para fallar en contra de los Estados ${ }^{13}$.

El párrafo 1 del artículo 5 dice: "un trato no menos favorable que el que otorgue a sus propios inversionistas y sus inversiones". Sin embargo, se agrega seguidamente:

Lo dispuesto en este Artículo no impide la adopción y aplicación de nuevos requisitos o restricciones legales a los inversionistas y sus inversiones siempre y cuando no sean discriminatorios. Se considerará que un trato es menos favorable si modifica las condiciones de competencia a favor de sus propios inversionistas y sus inversiones en comparación con los inversionistas de la otra Parte y sus inversiones.

\footnotetext{
${ }^{12}$ A diferencia del ACFI, ya existen TBI que han excluido los derechos administrativos. Por ejemplo, el TBI Australia-Hong Kong y en el de Australia-Indonesia, se establece que sólo se protege a las inversiones "que sean realizadas en acuerdo con las regulaciones y políticas aplicables en cada momento".

${ }^{13}$ Por ejemplo, en 2002 se invocó la cláusula de Trato Nacional en una demanda contra México en el marco del Tratado de Libre Comercio de América del Norte (TLCAN), caso Fireman's Fund Insurance Company vs. los Estados Unidos Mexicanos.
} 
Como vemos, la aclaración no acota el principio de Trato Nacional, que se mantiene igual que en los TBI. La diferencia es que hace explícito que se pueden modificar con posterioridad al tratado las reglas y requisitos a los inversionistas, siempre que se apliquen sin discriminación entre inversionistas extranjeros y nacionales. El ACFI acepta sin crítica este principio de no discriminación que hace tanto al Trato Nacional como al de Nación Más Favorecida. Aquí estamos frente a los principios básicos del libre comercio. Sin embargo, ninguno de los países llamados desarrollados ha llegado a esta condición sin un período de protección de sus industrias nacionales, es decir, dándoles privilegios frente a las extranjeras ${ }^{14}$.

El párrafo 2 de este mismo artículo 5 plantea el trato de Nación Más Favorecida. Afirma: "Sin perjuicio de las excepciones establecidas por su legislación en la fecha en que el presente Acuerdo entre en vigor, una Parte otorgará a los inversionistas de la otra Parte y a sus inversiones un trato no menos favorable que el que otorgue a los inversionistas de un Estado no Parte y a sus inversiones". Es importante resaltar que el ACFI hace referencia explícita a las excepciones marcadas por la ley nacional brasileña, pero no dice que actuales o futuras, por lo que sigue limitando la flexibilidad futura de la política exterior brasileña así como concesiones mayores a socios estratégicos.

En el párrafo $3^{\circ}$ el ACFI hace otras dos acotaciones importantes al principio de $\mathrm{Na}$ ción más Favorecida en el que se aclara lo siguiente:

Este Artículo no se interpretará como una obligación de una Parte para dar a un inversionista de la otra Parte o a sus inversiones el beneficio de:

- cualquier tratamiento, preferencia o privilegio que surja de:

(i) disposiciones relacionadas con solución de controversias en materia de inversiones, contenidas en un acuerdo de inversiones o en un acuerdo que contenga capítulo de inversiones;

(ii) o cualquier acuerdo comercial internacional, tales como una organización de integración económica regional, zona de libre comercio, unión aduanera o mercado común, actual o futuro, del cual cada Parte sea miembro o al que se adhiera en el futuro.

Sí resulta novedoso que el ACFI excluya directamente el uso del trato de Nación Más Favorecida en el caso de que una empresa quiera utilizar el sistema de solución de controversias inversor-Estado existente en tratados previamente firmados (en TLC o TBI). Brasil, como dijimos, no es parte del CIADI, pero México sí lo es, por lo cual una empresa podría usar ese canal para llevar a Brasil a un foro de arbitraje. Con esta salvedad, Brasil se cubre de esa posibilidad.

También es importante que excluya del Trato de Nación Más Favorecida cualquier privilegio o preferencia que surja de un acuerdo regional de integración actual o futuro. Esta acotación es importante, pero tiene una limitación: excluye el trato de Nación Más Favorecida sólo si se basa en un tratado formal, y con eso se quita flexibilidad para otorgar preferencias a países socios estratégicos en momentos de emergencia o crisis.

\footnotetext{
${ }^{14}$ Véase Han Joon Chang: "La inversión en la OMC, una trampa del norte" en http://www.amazon.com/Kicking-Away-Ladder-Development-Perspective/dp/1843310279, o la versión traducida al español por RMALC en www.rmalc.org/historico/libros
} 


\section{Expropiación (artículo 6)}

En este punto hay una diferencia muy relevante con los TBI tradicionales. El ACFI sólo pacta expropiaciones directas y no refiere a la "expropiación indirecta". La garantía que se otorga a los inversionistas es que la expropiación solo se hará por utilidad e interés público, de forma no discriminatoria, de conformidad de debido proceso legal, con pago expedito y a valor justo de mercado. Incluso es más detallado que otros TBI al garantizar que no se utilizarán artimañas para hacer disminuir su valor en el mercado. Como todos los TBI, el pago es libremente transferible fuera del país salvo las limitaciones que se consignan en el Artículo 9 (garantía de procedimientos contenciosos pendientes o crisis de balanza de pagos, de conformidad con las reglas del FMI que deben de aplicarse de forma no discriminatoria). Estas limitaciones son en general iguales a las que se encuentran en los TBI, pero es más detallado en garantizarle al inversionista expropiado que se le pagará al valor de mercado.

\section{Compensaciones por pérdidas (artículo 7)}

Este artículo tampoco tiene que ver con el concepto de "expropiación indirecta" de los TBI. Se refiere sólo a compensaciones por guerra, conflictos armados, insurrecciones, estado de emergencia nacional $u$ otros acontecimientos similares. El compromiso es que se hará sin discriminar respecto a los inversionistas nacionales o de otras naciones (Trato Nacional y de Nación Más Favorecida).

Aquí también se deja afuera la noción de "expectativas legítimas" que se refiere a ganancias eventuales de las empresas inversionistas, es decir, sobre una ganancia que aún no se ha realizado. Algunos tribunales arbitrales han considerado que la elaboración de un proyecto y las negociaciones respecto del mismo serían una inversión que genera expectativas de éxito y respecto de las cuales el inversionista puede reclamar si no se concreta y ejecuta (Sornarajah, 2010).

\section{Libre flujo de capitales (artículo 9)}

Garantiza el absoluto libre flujo de capitales, salvo garantía de procedimientos contenciosos o crisis de balanza de pagos de conformidad con las reglas del FMI. Aquí no hay diferencia con los TBI tradicionales. Con ello Brasil renuncia a ciertos controles de flujo de capitales que ha tenido en el pasado. Tiene la ventaja de que expresamente excluye del ámbito la aplicación de este tratado las inversiones especulativas.

Sin embargo, sí incluye los créditos entre empresas relacionadas. Las empresas transnacionales suelen invertir en sus filiales bajo la forma de créditos y de esa forma reintegrarlos a la matriz sin que se considere fuga de capitales y ello puede constituirse en una sangría permanente de recursos, que además permite evadir los mecanismos que pueden implementar los Estados para evitar la fuga de capitales. Tal es el caso de Ecuador con el impuesto a la salida de divisas.

Por otra parte, el hecho de poder limitar el libre flujo de capitales por problemas de balanza de pagos según las reglas del FMI resulta limitado. Ya hay experiencia sobre los riesgos que ello puede implicar. Citemos solo dos ejemplos; México, en diciembre de 2014, no había entrado en crisis de balanza de pagos, pero la fuga masiva de capitales llevó a la devaluación y a la crisis de balanza de pagos; a tener que declararse en cesación 
temporal de pagos y a entrar en una de las crisis con mayor costo social de princípios de siglo. El otro ejemplo es el de los países sin moneda propia, que al no poder imprimir dinero la fuga de capitales lleva a una falta de circulante y todos los problemas que ello acarrea. También Ecuador planteó la necesidad de restringir la salida de divisas, incluso limitando importaciones, debido al riesgo de llegar a una falta de circulante y a una crisis de balanza de pagos (el FMI no aceptó el planteo).

\section{Medidas tributarias (artículo 10)}

En el ACFI se afirma que nada de lo pactado evitará que se hagan cumplir y se tomen las medidas necesarias para hacer cumplir las disposiciones de la legislación interna en materia tributaria, siempre y cuando se hagan de manera no discriminatoria (Trato Nacional). Esta exclusión es importante dada la enorme elusión, defraudación fiscal o incluso formas de flujos ilícitos de capital que han significado una enorme sangría de recursos de los países latinoamericanos. Este es un problema creciente: las grandes empresas globales han demostrado una enorme creatividad para encontrar formas "legales" de no pagar o pagar mucho menos impuestos, facilitados precisamente por el libre comercio.

Es importante resaltar que el tratado excluye explícitamente en materia tributaria el trato de Nación Más Favorecida por lo que un inversionista no podrá exigir se le aplique lo dispuesto en algún tratado de no doble tributación del que no forma parte.

\section{Responsabilidad Social Corporativa (artículo 13)}

La inclusión de la Responsabilidad Social Corporativa (RSC) es una novedad en estos acuerdos. El ACFI plantea una serie de principios que guían la actuación de los inversionistas, pero se puntualiza que se trata de normas voluntarias. Se establece que: "Los inversionistas y sus inversiones se esforzarán por lograr el más alto nivel posible de contribución al desarrollo sostenible del Estado anfitrión y la comunidad local, a través de la adopción de un alto grado de prácticas socialmente responsables". Asimismo, el artículo sigue: "deberán desarrollar sus mejores esfuerzos para cumplir con los siguientes principios y normas voluntarias para una conducta empresarial responsable y coherente con las leyes vigentes aplicables por el Estado anfitrión receptor de la inversión".

Las palabras claves en dicha cláusula son "se esforzarán" a "desarrollar sus mejores esfuerzos", lo cual claramente no impone obligaciones, ni requisitos de desempeño a los inversionistas. Otros tratados que se negociaron recientemente como el Tratado TransPacífico (TPP) también incluyen cláusulas de RSC, por lo cual se observa que se sigue actualmente una tendencia a hablar de las responsabilidades empresarias en el marco de las inversiones extranjeras. No obstante, también en ese tratado se establece la voluntariedad de dicho marco regulatorio, lo cual le quita fuerza jurídica.

\section{Gobernanza institucional del Acuerdo y prevención de contro- versias (parte III)}

Aquí se plantean algunas novedades que saltan a la vista al compararlos con los TBI. En el ACFI se establece un procedimiento de solución de controversias mucho más minucioso que en los TBI, el cual tiene aquí el objetivo de prevenir las disputas. Lo central 
es la creación de un Comité Conjunto intergubernamental que tiene como funciones no sólo administrar el acuerdo y velar por el cumplimiento de sus objetivos (a los que nos referiremos más adelante), sino solucionar amigablemente las disputas y evitar llegar a un arbitraje. Para ello, se crea la figura del Ombudsman, compuesto por los sectores empresarios que son incorporados en el diálogo con el fin de reducir al mínimo la posibilidad de que se desarrollen las controversias.

Revisemos las funciones y características de este Comité Conjunto, además de la solución de controversias:

a) está conformado por representantes de los gobiernos de ambas Partes, que deben reunirse al menos una vez al año, con el fin de mantener la "Administración del Acuerdo" (artículo 14).

b) recoge la información sobre las necesidades y tipos de inversión que se desean así como las posibilidades de asociaciones público-privadas. Esto muestra una voluntad de involucramiento más fuerte de los Estados en la revisión cotidiana del cumplimiento de los objetivos del Acuerdo. Ofrece incluso más posibilidades de promover IED en las áreas que se consideran más convenientes, así como de no promoverla en otras. Por supuesto, nada de esto impide la libre iniciativa de los inversionistas. Los artículos 14, 15, 16 y 18 le dan operatividad a estas funciones del Comité conjunto.

c) tiene entre sus funciones y responsabilidades "consultar al sector privado y a la sociedad civil, cuando resulte pertinente, sobre cuestiones específicas relacionadas con los trabajos del Comité Conjunto". Esto es novedoso ya que abre a la participación de otros actores que no son ni el inversionista extranjero ni el Estado, aunque no se especifica de qué modo operaría tal consulta (artículo 14).

d) junto con el Comité operan Puntos Focales Nacionales de cada Parte (también denominados "Ombudsman") que tienen como principal responsabilidad "el apoyo a los inversionistas de la otra Parte en su territorio" (artículo 15): la Cámara de Comercio Exterior (CAMEX) en Brasil, y la Comisión Nacional de Inversiones Extranjeras en México. El Ombudsman cumple un rol de pivot o bisagra entre los inversionistas y el Comité Conjunto, con el fin de facilitar el diálogo y prevenir conflictos. También en el artículo 18 se explica que: "los Puntos Focales Nacionales u 'Ombudsmen' actuarán en forma coordinada entre sí y con el Comité Conjunto con el fin de prevenir, administrar y resolver las controversias entre las Partes". Asimismo se promueve que las Partes intercambien información para las inversiones recíprocas en relación con las oportunidades de negocio, los procedimientos y requisitos para la inversión a través del Comité Conjunto o del Ombudsman. Esto resulta relevante más allá de la propia prevención de demandas de arbitraje, ya que con tal seguimiento se podría garantizar algunos de los puntos que aparecen planteados desde el Preámbulo, promoviendo el respeto al "espíritu" del tratado con el tipo de inversiones que se pueden fomentar desde las Partes (artículo 16).

De este modo, se establece un minucioso mecanismo de solución de controversias para llegar a un acuerdo de consenso en caso de disputa. El título mismo de la tercera parte del Acuerdo es elocuente: "prevención de controversia". El ACFI habla de "prevenir, administrar y resolver las controversias entre las Partes": "Antes de iniciar un procedimiento de arbitraje, de conformidad con el Artículo 19 del presente Acuerdo, toda controversia entre las Partes se evaluará a través de consultas y negociaciones entre las Partes y será previa- 
mente examinada por el Comité Conjunto" (artículo 19, párrafo 1). El rol del Comité Conjunto es entonces central para intentar disuadir del recurso del arbitraje ${ }^{15}$.

Una vez agotado este mecanismo, cualquiera de las Parte puede decidir ir al arbitraje internacional. En tal caso, aparecen diferencias importantes con los TBI:

1) El arbitraje será entre Estados y no inversionista-Estado (artículo 19, párrafo 1), estableciendo para ello un tribunal ad hoc designado por las Partes. En caso de no llegar a un acuerdo sobre los árbitros a ser designados, las Partes pueden invitar al Presidente de la Corte Internacional de Justicia a hacer las designaciones necesarias (artículo 19, párrafo 6).

2) El objetivo primordial del arbitraje es poner la medida impugnada en conformidad con lo pactado en este Acuerdo y no imponer sanciones. Pero las Partes podrán acordar que el panel arbitral pueda examinar si hay perjuicios que indemnizar (artículo 19, párrafo 2 ).

3) No se puede recurrir al arbitraje para ninguna controversia previa a la firma de este Acuerdo, ni tampoco ante una medida existente antes de que esté vigente (artículo 19 párrafo 3). Esto acaba con la retroactividad típica de los TBI, donde se manifiesta que están cubiertas por los tratados las inversiones y controversias previas a la firma del mismo.

4) Se plantean criterios que deben cumplir los árbitros y se les somete a las normas y procedimientos de la OMC (Artículo 19, párrafo 7) como lo ha hecho Brasil en los tratados firmados como parte de MERCOSUR.

\section{Vigencia (artículo 21)}

El ACFI excluye la cláusula de sobrevivencia que se encuentra presente en la mayoría de los TBI. Cualquiera de las Partes puede dar por concluido el acuerdo cuando lo desee, y en caso de no llegar a un acuerdo acerca de la terminación del tratado, con la sola notificación de una de las Partes se dará por terminado el Acuerdo a los 365 días de tal notificación. Esto se diferencia de los TBI clásicos que tienen un período de ultra vigencia por 5, 10, o 15 años más.

\section{Reflexiones finales}

Luego de hacer un recorrido minucioso por el ACFI, vemos que existen cambios sustanciales al compararlo con los TBI. Repasemos los puntos más relevantes: a) acota las inversiones cubiertas y explícitamente excluye las de cartera o especulativas; b) limita la retroactividad para inversiones previas a la firma; c) excluye la llamada expropiación indirecta; d) contiene salvaguardas para mantener la posibilidad de regulaciones prudenciales en el sector financiero; e) mejora el mecanismo de solución de disputas sobre todo al incluir la posibilidad de que los inversores sean evaluados en su desempeño; f) incorpora una institucionalidad propia con el objetivo de velar por el cumplimiento de los objetivos del acuerdo y de minimizar las controversias; g) limita el alcance de algunas de las cláusulas; h) acota a un máximo de 1 año la cláusula de sobrevivencia.

${ }^{15}$ El mecanismo de solución de disputas es similar al que ya había aceptado Brasil como parte del Mercosur en el TLC vigente con Israel (y los firmados pero aún no ratificados hasta 2015 con Marruecos y Egipto). 
Con respecto al sistema de solución de controversias planteado por el ACFI, queremos aquí dejar algunos puntos planteados para posteriores debates sobre este tipo de nuevos mecanismos.

a) EI ACFI plantea que la ley aplicable para solucionar las controversias es el texto del tratado y no la legislación del país receptor. Actualmente se discute la pertinencia de volver a la solución de disputas en los tribunales nacionales y según la legislación del país receptor, tal como sostienen ciertos sectores de académicos (Corti, 2005; Teitelbaum, 2010) y las organizaciones de la sociedad civil. Algunos aceptan que se pueda recurrir a un tribunal externo sólo para que dictamine si se siguió el debido proceso, pero no sobre la sustancia de la controversia.

b) En cuanto a los criterios para la actuación de los árbitros sólo remite a los de la OMC. Habría que discutir si las normas de la OMC son suficientes. Este punto es fundamental basado en la experiencia en el CIADI, donde el proceso de recusación de árbitros ha mostrado ser casi imposible (Eberhardt y Olivet, 2012; CAITISA, 2015). El ACFI no incluye cláusulas suficientes para garantizar la imparcialidad de los árbitros, ni mecanismos y criterios para su recusación.

c) Para la solución de controversias, se puede recurrir a un panel arbitral ad hoc, pero también a "otro mecanismo para solución de controversias entre Estados en materia de inversiones" (artículo 19 párrafo 4). No queda claro cuáles son estos "otros mecanismos" de los que se habla en este Acuerdo, lo cual resulta peligroso por la amplitud de los términos.

d) Consideramos que si se acepta la posibilidad de recurrir a un mecanismo internacional de solución de controversias, resulta mejor un tribunal permanente con jueces profesionales y permanentes y no árbitros ad hoc que son pagados por los contendientes. Se ha planteado la creación de una corte internacional o regional con capacidad de imponer sanciones como mecanismo idóneo mientras haya TBI vigentes; sin embargo, como dijimos, actualmente una corriente de académicos y de organizaciones sociales proponen que en los nuevos acuerdos se establezca que las controversias se resuelvan en tribunales nacionales y según la legislación del país receptor.

e) El hecho de que las disputas se arreglen entre Estados y no inversor-Estado puede tener ventajas, pero también presenta algunos problemas, a saber:

1) Un asunto problemático es que la controversia que suscite un inversor pasa a ser cuestión de política exterior de la Parte de donde éste proviene. Esto implica una politización de la controversia (Pascual, 2016) que inicia un inversor, cuando en los TBI tradicionales el modo de acción es privado: el inversor acciona contra el Estado donde tiene su inversión, sin necesidad de que medie "su" Estado $^{16}$. En cambio, ahora el Estado debe actuar en el marco del ACFI para solucionar la controversia del privado con la contraparte. Esto vuelve a sepultar la doctrina Calvo. Además, se puede interpretar que el interés de Brasil que subyace a este mecanismo es la existencia de grandes empresas estatales que in-

\footnotetext{
${ }^{16}$ De todos modos, los gobiernos de los Estados de origen del inversor han tenido un rol de presionar sobre el Estado demandado para que solucione la controversia. Un caso paradigmático fue el de las demandas de empresas españolas contra la Argentina post-devaluación, donde el presidente Rodríguez Zapatero solicitó al entonces presidente Néstor Kirchner que actuara favorablemente frente a las empresas de esa nacionalidad que habían presentado demandas en el CIADI.
} 
vierten en el exterior. Esta cuestión llama a la necesidad de hacer un seguimiento al tipo de inversiones (públicas o privadas) que operan tanto en México como en Brasil.

2) Implica una mayor asimetría de poder en el arreglo de las disputas. Si se firmara este tipo de acuerdos con alguno de los países del G-8 el problema de la asimetría podría ser aún mayor que el mecanismo inversor-Estado. Esto se hace evidente en, por ejemplo, la capacidad de negociación de estos Estados para "sugerir" que no se demande a una de sus empresas, recordándonos su poder en los organismos financieros internacionales.

3) Puede aumentar el problema de que nacionales del país demandado recurran al arbitraje internacional. Tanto los TBI como el ACFI dejan en claro que los inversores nacionales no pueden recurrir al arbitraje internacional ni a las prerrogativas de estos tratados. Sin embargo, hay experiencias de que se logra burlar esta limitación, creando o registrando en el exterior una empresa que es propiedad mayoritaria de un nacional del país donde opera. Estos casos pueden ser aún más difíciles de bloquear en un mecanismo de disputas entre Estados, ya que si el Estado en el que está registrada la empresa lleva el caso a arbitraje, es mucho más complicado el litigio que si fuera la empresa la que lo presenta ${ }^{17}$.

f) Como ya hemos dicho, el ACFI no contiene obligaciones vinculantes para las empresas, sólo voluntarias en el marco de la responsabilidad social. Sin embargo, surgen muchas preguntas cuyas respuestas no son claras en el texto del ACFI. ¿Se puede demandar a una empresa extranjera por el incumplimiento de su propio código de ética o de responsabilidad social corporativa? Nuestra lectura es que se puede discutir en el Comité Conjunto y eso ya es un pequeño avance de cierta bilateralidad. Pero, ¿se puede llevar el asunto al arbitraje internacional, vía el Estado donde opera la inversión? Dejamos la pregunta abierta para que los abogados expertos en derecho comercial internacional lo investiguen. Se le puede demandar en tribunales nacionales, si viola expresamente la ley. Pero se le puede demandar nacionalmente por violación de sus propios códigos de ética o responsabilidad social. Este punto entonces no queda claro.

En este trabajo hemos mostrado las diferencias entre el ACFI y los TBI, señalamos algunas de sus ventajas y limitaciones. La propuesta brasileña no es la única. Como explicamos, existe hoy un amplio y variado proceso internacional de cuestionamiento del sistema actual sobre inversiones extranjeras, no sólo desde la academia, los organismos internacionales y los gobiernos. Las redes internacionales de organizaciones sociales y civiles trabajan desde hace más de dos décadas en un modelo alternativo integral al actual modelo de protección de los inversores extranjeros y sus inversiones a costa de derechos humanos y de la naturaleza ${ }^{18}$. Es necesario entonces seguir discutiendo pro-

${ }^{17}$ En numerosos casos los inversionistas han "cambiado de nacionalidad" con el único fin de utilizar las condiciones contractuales más favorables de otro TBI (el caso Bechtel vs. Bolivia es notorio en este sentido).

${ }^{18}$ Entre las propuestas alternativas surgidas desde la sociedad civil podemos destacar cuatro que tienen un altísimo grado de convergencia en sus puntos esenciales. Las primeras surgen en América del Norte al calor de la lucha contra el TLCAN y se reúnen en el documento de la Alianza Social Continental titulado "Alternativas para las Américas". La primera versión es de 1998 y se fue modificando al calor de la lucha contra el ALCA. Se publicó en francés, inglés, español, portugués, alemán y creole. La quinta versión se publicó en octubre de 2005. Puede verse en http://www.rmalc.org/historico/libros.htm. La se- 
puestas integrales que garanticen la supremacía real de los derechos humanos, políticos, sociales, económicos, de la naturaleza y de los pueblos, por encima de cualquier otro derecho.

\section{Bibliografía}

Actis, Esteban (2012) "Brasil frente a los Tratados Bilaterales de Inversiones: disyuntivas de su política exterior reciente frente al proceso de internacionalización de capitales brasileños" en Revista NEIBA, Cadernos Argentina-Brasil, volumen 1, número 1.

Alianza Social Continental (1998) "Alternativas para las Américas", 5a versión octubre de 2005, RMALC, México. Puede verse en http://www.rmalc.org/historico/libros.htm.

Arroyo, Alberto (2013) "La inversión extranjera directa entre la Unión Europea, América Latina y el Caribe" en ¿Hacia dónde van las relaciones América Latina y la Unión Europea? Ediciones ALOP-México. Re-editado en La inversión extranjera directa entre la Unión Europea, América Latina y el Caribe por Rosa Luxemburgo et al, Ecuador, febrero 2014.

CAITISA (2015) Auditoría Integral Ciudadana de los Tratados de Protección Recíproca de Inversiones y del Sistema de Arbitraje en Materia de Inversiones; Informe Ejecutivo, Secretaría Nacional de Planificación y Desarrollo. Quito, Ecuador, próxima publicación.

CEPAL (2012) La Inversión Extranjera Directa en América Latina y el Caribe 2011; Colección Informes Anuales, Santiago de Chile.

Colectivo (Campaña global: desmantelemos el poder corporativo 2014) “Tratado Internacional de los Pueblos para el Control de las Empresas Transnacionales", TNI, Bruselas/Amsterdam. Puede verse en http://omal.info/IMG/pdf/tratado_de_los_pueblos_-_castellano.pdf .

Corti, Arístides (2005) "Acerca de la inmunidad del estado frente a los tribunales arbitrales y judiciales externos (CIADI y otros)", en Revista Realidad Económica (Buenos Aires), número 211.

Eberhardt, Pia y Olivet, Cecilia (2012) “Cuando la injusticia es negocio; cómo las firmas de abogados, árbitros y financiadores alimentan el auge de arbitraje sobre inversiones", CEO-TNI, Bruselas/Amsterdam. Puede verse en https://www.tni.org/files/download/cuando_la_injusticia es negocio-web.pdf

gunda propuesta se encuentra en el documento "Hacia la construcción de un marco legal alternativo a los Acuerdos Internacionales de Inversión", publicado por el Grupo de Trabajo sobre Inversiones de las Américas en mayo de 2014 y puede verse en

http://rqic.alternatives.ca/IMG/IMG/pdf/Llamamiento_Regimen_Alt_Inversiones_mayo2014_ESP.pdf. La tercera propuesta es el "Tratado Internacional de los Pueblos para el Control de las Empresas Transnacionales", elaborado en 2014 en el marco de la "Campaña global: desmantelemos el poder corporativo", y puede verse en http://omal.info/IMG/pdf/tratado_de_los_pueblos_-_castellano.pdf . El cuarto documento está aún inédito y se elaboró como recomendación al gobierno de Ecuador al interior de la CAITISA (CAITISA, 2015). 
Echaide, Javier (2009) "Responsabilidad Social Empresaria: un sobrevuelo por la Norma ISO 26000" en Revista Lan Harremanak (País Vasco), número 20-21.

Fleury y otros (2010) "El camino se hace al andar: la trayectoria de las multinacionales brasileñas", Universia Business Review, $\mathrm{n}^{\circ} 25$.

Ghiotto, Luciana (2017) “¿UNCTAD pro-desarrollo o pro-liberalización? Un estudio de los cambios en el organismo a la luz de las políticas sobre inversiones" en Echaide (comp.) Problemáticas en torno al CIADI y los tratados bilaterales de protección de inversiones: su impacto en los derechos humanos y otras áreas del derecho internacional, Buenos Aires, Facultad de Derecho UBA, en prensa.

Grupo de trabajo sobre Inversiones (mayo 2014) “Hacia la construcción de un marco legal alternativo a los Acuerdos Internacionales de Inversión", RMALC, México. En http://rqic.alternatives.ca/IMG/IMG/pdf/Llamamiento_Regimen_Alt_Inversion es_mayo2014_ESP.pdf.

Hallward-Driemeier (2003) “Do Bilateral Investment Treaties Attract FDI? Only a bit...and they could bite", World Bank Policy Research Working Paper.

Han Joon Chang: "La inversión en la OMC, una trampa del norte" en http://www.amazon.com/Kicking-Away-Ladder-DevelopmentPerspective/dp/1843310279 o la versión traducida al español por RMALC en www.rmalc.org/historico/libros

Morosini, Fabio y Ratton, Michelle (2015) "The Brazilian Agreement on Cooperation and Facilitation of Investments (ACFI): A New Formula for International Investment Agreements?" en Investment Treaty News, página web de IISD.

Pascual, Rodrigo F. (2016) La Argentina y el ALCA: de la adhesión incondicional a la oposición abierta, Tesis para optar por el título de Doctor en Ciencias Sociales, UBA; en https://www.academia.edu/25870863/LA_ARGENTINA_Y_EL_ALCA

Poulsen, Lauge (2010) "The Importance of BITs for Foreign Direct Investment and Political Risk Insurance: Revisiting the Evidence", Yearbook on International Investment Law and Policy 2009/2010 (Nueva York: Oxford University Press).

Sornarajah, M. (2010) The international Law on Foreign Investment (Nueva York: Cambridge University Press).

Teitelbaum, Alejandro (2010) "Los tratados internacionales, regionales, subregionales y bilaterales de libre comercio" en Cuaderno Crítico (Ginebra), número 7.

UNCTAD (2013) "Towards a new generation of International Investment Policies: UNCTAD's Fresh Approach to Multilateral Investment Policy Making", IIA Issue Notes, $\mathrm{n}^{\circ} 5$ (United Nations: New York and Geneva).

UNCTAD (2014) "Reform of the IIA regime: four paths of action and a way forward", IIA Issue Notes, $\mathrm{n}^{\circ} 3$ (United Nations: New York and Geneva).

Yackee, Jason (2010) “Do Bilateral Investment Treaties Promote Foreign Direct Investment? Some Hints from Alternative Evidence", Universidad de Wisconsin, Legal Studies Research Paper Series Paper No. 1114. 